\title{
sp $^{2}$-Hybridized Carbon-Containing Block Copolymer Templated Synthesis of Mesoporous Semiconducting Metal Oxides with Excellent Gas Sensing Property
}

\author{
Yidong Zou, ${ }^{\dagger}$ Xinran Zhou, ${ }^{\dagger}$ Yongheng Zhu, ${ }^{\dagger,}$ Xiaowei Cheng, ${ }^{\dagger}$ Dongyuan Zhao, ${ }^{\dagger}$ \\ and Yonghui Deng*,†
}

${ }^{\dagger}$ Department of Chemistry, State Key Laboratory of Molecular Engineering of Polymers, Shanghai Key Laboratory of Molecular Catalysis and Innovative Materials, iChEM, Fudan University, Shanghai 200433, China

${ }^{\ddagger}$ College of Food Science and Technology, and Laboratory of Quality \& Safety Risk Assessment for Aquatic Products on Storage and Preservation (Shanghai), Ministry of Agriculture, Shanghai Ocean University, Shanghai 201306, China

CONSPECTUS: In recent years, rational design of ordered mesoporous metal oxides, especially metal oxide semiconductors with adjustable pore architecture and framework compositions, has aroused extensive research interest owing to their unique electronic structures, long-range ordered porous framework, uniform mesopore size, and high specific surface area. Research on mesoporous materials has been booming in the past 30 years, and many synthesis methods have been developed, such as templating methods based on amphiphilic copolymers as soft templates or mesoporous carbon/silica as hard templates, respectively. Soft-templating synthesis has been considered as one of

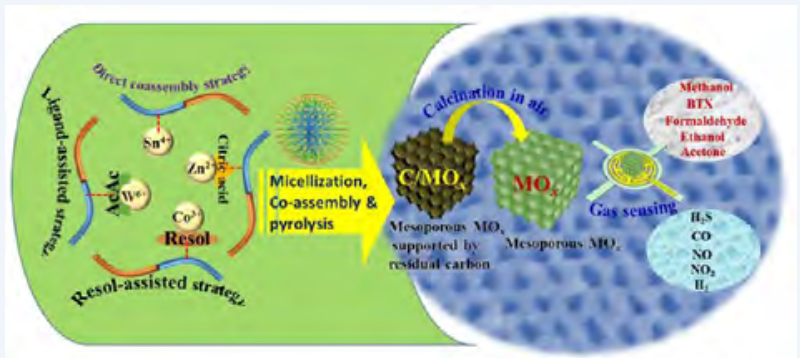
the most efficient and flexible methods in designing ordered mesoporous materials through the controllable interfacial induced coassembly process. However, most commercial amphiphilic copolymers, such as poly(ethylene oxide)-b-poly(propylene oxide) based Pluronic-type ones, suffer the drawback of poor thermal stability, because they are too easy to be decomposed even in inert atmosphere. Therefore, they are difficult to support the structures of mesoporous metal oxides under high calcination temperatures $\left(>400{ }^{\circ} \mathrm{C}\right)$. To solve this challenge, we designed new amphiphilic block copolymers with high content of $\mathrm{sp}^{2}$-hybridized carbon in the hydrophobic segments that were relatively stable and could be in situ converted into residual carbon to support the mesoporous structure, via living free radical polymerization. We developed a variety of novel synthesis methods based on $\mathrm{sp}^{2}$-hybridized carbon-containing block copolymer, such as ligand-assisted assembly and resol-assisted assembly strategies, achieving a controllable and versatile synthesis of mesoporous semiconducting metal oxides with excellent gas sensing performance. In this Account, we first outline the features of $\mathrm{sp}^{2}$-hybridized carbon-containing block copolymers synthesized via living free radical polymerization, particularly their pyrolysis behavior in converting into residual carbon. Combining the solvent evaporation induced coassembly and the carbon-supported crystallization strategies, we realized the rational design of various ordered mesoporous semiconducting metal oxides (e.g., $\mathrm{WO}_{3}, \mathrm{SnO}_{2}, \mathrm{Co}_{3} \mathrm{O}_{4}, \mathrm{In}_{2} \mathrm{O}_{3}, \mathrm{TiO}_{2}, \mathrm{ZnO}$ ) and the regulation of their architectural features. To overcome the fast hydrolysis rate of metal precursors and weak interaction between block copolymers and metal precursors, we developed efficient ligand-assisted (e.g., acetylacetone and acetic acid) coassembly and resol-assisted coassembly methods to retard hydrolysis behavior and enhance the interaction via hydrogen bonds, covalent bonds, electrostatic interactions, etc. We also highlight the applications of these ordered mesoporous semiconducting metal oxides of both $n$-type and p-type in gas sensing fields, and they show tremendous sensing performance due to their abundant active sites on electron depletion layer and rapid gas diffusion via accessible pore channels. Finally, on the basis of the classic surface-electron depletion layer model, we elucidated in depth the surface catalytic reactions between the target gas molecules and the activated species (e.g., the adsorbed oxygen species) in the surface of mesoporous metal oxides during sensing process. These newly developed soft-templating synthesis methods that rely on $\mathrm{sp}^{2}$ hybridized carbon-containing block copolymers will open a new avenue for the design and application of ordered mesoporous semiconducting metal oxides in various fields.

\section{INTRODUCTION}

Owing to their miraculous electrical, magnetic, and thermal properties, metal oxide semiconductors have been extensively studied for catalysis, sensors, energy storage, etc. ${ }^{1-3}$ With the progress of technology about Internet of things, various intelligent devices, particularly gas sensors based on highperformance sensing materials, have gained unprecedented attention. ${ }^{4}$ Ordered mesoporous semiconducting metal oxides (OMSMOs) have recently emerged as ideal sensing materials due to their highly porous structure with suitable pore size (2$50 \mathrm{~nm}$ ), outstanding mass transport efficiency, and high specific surface area. $^{5-7}$ The attempt to synthesize OMSMOs via softtemplating approach can be traced to Yang's work on various metal oxides with semicrystalline frameworks, including $\mathrm{TiO}_{2}$, $\mathrm{ZrO}_{2}, \mathrm{Al}_{2} \mathrm{O}_{3}$, and $\mathrm{Nb}_{2} \mathrm{O}_{5}$ via coassembly between commercial

Received: November 25, 2018 
amphiphilic block copolymers and metal salts. ${ }^{8}$ Despite the difference in chemical component of the framework, the common feature of soft-templating synthesis is that the coassembly is based on various interactions between the precursor and hydrophilic segments in the template molecules. $^{9,10}$

Currently, lots of ordered mesoporous materials with amorphous frameworks, including silica and carbon, have been reported based on commercial soft templates (e.g., quaternary ammonium salts and poly(ethylene ether) series). ${ }^{11-13}$ By contrast, it has remained a great challenge to controllably synthesize high-quality OMSMOs through either soft- or hardtemplating approaches. ${ }^{14,15}$ It is mainly because most previous attempts to OMSMOs exclusively relied on the commercially widely available Pluronic-type templates. These templates possess low molecular weight and decomposition temperature, and they can be decomposed too fast even at low temperature region $\left(<350{ }^{\circ} \mathrm{C}\right) .{ }^{16,17}$ Thus, it is unable to support the reorganization and crystallization of the pore walls during template removal at high temperatures (usually $>400{ }^{\circ} \mathrm{C}$ ), leading to metal oxides with low porosity, disordered porous structure, and low surface areas. These drawbacks seriously hamper their applications in many fields, in which a fast mass transport of guest molecules and efficient host-guest interaction between molecules and solid frameworks are required.

To solve the above problems, we designed various $\mathrm{sp}^{2}$ hybridized carbon-containing block copolymers with lower oxygen content and high thermal stability using controllable living polymerization methods. ${ }^{18}$ On the basis of the rich phase behaviors of these block copolymers and their interaction with inorganic precursors, we realized the rationally controllable design and synthesis of various OMSMOs (e.g., $\mathrm{TiO}_{2}, \mathrm{WO}_{3}$, $\left.\mathrm{Nb}_{2} \mathrm{O}_{5}, \mathrm{SnO}_{2}, \mathrm{In}_{2} \mathrm{O}_{3}, \mathrm{ZnO}, \mathrm{Co}_{3} \mathrm{O}_{4}\right)$. These materials possess ordered mesostructure, high surface area $\left(120-200 \mathrm{~m}^{2} \cdot \mathrm{g}^{-1}\right)$, tunable pore size $(8.0-30 \mathrm{~nm})$, highly crystalline framework, and promising sensing values. After more than 10 years' research on the soft-templating synthesis of mesoporous materials, we are now at a point where we can present a coherent account of various reliable methods for effective synthesis of OMSMOs with excellent gas sensing performance.

\section{SP2 -HYBRIDIZED CARBON-CONTAINING BLOCK COPOLYMERS}

With the development of templating synthesis concept, various functional mesoporous metal oxides have been extensively explored for applications in different fields. Mesoporous structures are mainly synthetically generated from the softtemplating approaches based on interface coassembly of amphiphilic molecules and framework precursors. Although the synthetic route is kaleidoscopic and can produce different mesoporous structures with different properties, the assembly process follows liquid crystalline pathway based on the microphase separation of block copolymers.

Using commercial Pluronic-type poly(ethylene oxide)- $b$ poly(propylene oxide) copolymers (e.g., P123 and F127) as structure directing agent can only generate relatively small mesopores size $(<10 \mathrm{~nm})$ and semicrystalline framework, due to the short chain length of poly(propylene oxide) PPO block and poor thermal stability of the template molecules. Thanks to advances in the field of polymer synthetic chemistry, various new amphiphilic block copolymers, especially those non-Pluronic type ones, have been designed and applied for the controllable synthesis of OMSMOs with crystalline or amorphous ordered mesoporous framework. ${ }^{19,20} \mathrm{New}$ amphiphilic block copolymers, such as poly(isoprene)- $b$-poly(ethylene oxide) (PI- $b$ $\mathrm{PEO})$, poly(styrene- $b$-2-vinylpyridine- $b$-ethylene oxide) (PS- $b$ PVP- $b$-PEO), poly(ethylene oxide)- $b$-poly(styrene) (PEO- $b$ PS), and poly(styrene)- $b$-poly(2-vinylpyridine) (PS- $b$-P2VP) usually consist of hydrophilic blocks (i.e., PEO, poly(2vinylpyridine) (P2VP) and poly(4-vinylpyridine) (P4VP)) that can interact with inorganic precursors and hydrophobic blocks (i.e., PS, PI, polybutadiene (PB), and polyacrylonitrile (PAN)). ${ }^{19-24}$ These copolymers possess high carbon content, lower oxygen content, and rich $\mathrm{sp}^{2}$-hybridized-carbon atoms in the hydrophobic block, which enables them to be carbonized under inert conditions in the assembled mesostructures to support the crystalline frameworks under high temperatures. Thus, the target OMSMOs with well-reserved mesostructures and highly crystalline walls can be obtained after removal of residual carbon by further calcination in air at a temperature lower than that for carbonization. In 2008, Lee et al. ${ }^{20}$ reported a method combining soft structure-directing assemblies and hardtemplating chemistries, termed "CASH" method, and they synthesized many highly crystalline mesoporous metal oxides by using poly(ethylene oxide)- $b$-polyisoprene with rich $\mathrm{sp}^{2}$ hybridized-carbon as the soft template. ${ }^{25,26}$ Inspired by this method, our group designed amphiphilic block copolymers PEO-b-PS with different molecular weights and hydrophilic/ hydrophobic ratios, via the well-developed atom transfer free radical polymerization (ATRP) method, which is easy to learn even for those who have no experience in polymer synthesis. ${ }^{27,28}$ In the ATRP synthesis process, using $\mathrm{PEO}-\mathrm{Br}$ with various molecular weights (i.e., $2000-10000 \mathrm{~g} \cdot \mathrm{mol}^{-1}$ ) as a macroinitiator, adjusting the polymerization time of styrene monomer, we obtained high molecular weight soft templates (10000$50000 \mathrm{~g} \cdot \mathrm{mol}^{-1}$ ) with different chain lengths of hydrophilic PEO and hydrophobic PS blocks. Similarly, other amphiphilic block copolymers with PEO hydrophilic block can be readily synthesized through above polymerization reaction, and simply changing the reaction conditions, one can effectively adjust target molecular composition and chain length of templates, which is extremely beneficial for the controllable design and synthesis of OMSMOs.

\section{CONTROLLABLE ASSEMBLY SYNTHESIS OF OMSMOS}

\subsection{Different Forms of Assembly}

Recently, with the progress in understanding the coassembly process of amphiphilic block copolymers and different precursors in complex solutions, our group realized the controllable synthesis of a series of OMSMOs based on $\mathrm{sp}^{2}$ hybridized carbon-containing block copolymers. Emerging approaches have brought about high-quality OMSMOs, such as solvent evaporation induced coassembly (EICA), which have opened a door in large-scale production of OMSMOs. EICA usually occurs in a typical nonaqueous phase synthesis process, which depends on the kinetically induced evaporation of good solvent (e.g., tetrahydrofuran (THF), chloroform, dioxane) to reach critical concentration of comicellization of copolymers cooperatively assembling with inorganic precursor species, leading to OMSMOs after structure fixing and removal of template molecules. ${ }^{29,30}$ The continuous evaporation of good solvent causes the self-assembly of amphiphilic block copolymers with associated inorganic species into ordered mesostructures (i.e., liquid crystalline phases) in the nonaqueous 
(A)

(C)
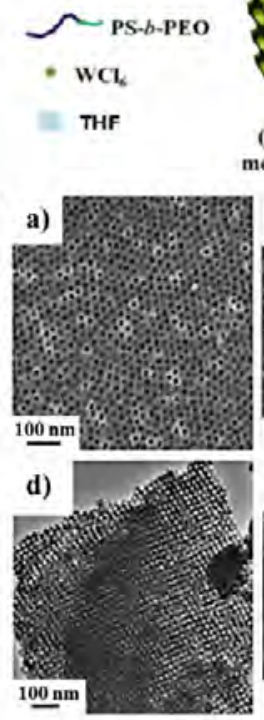
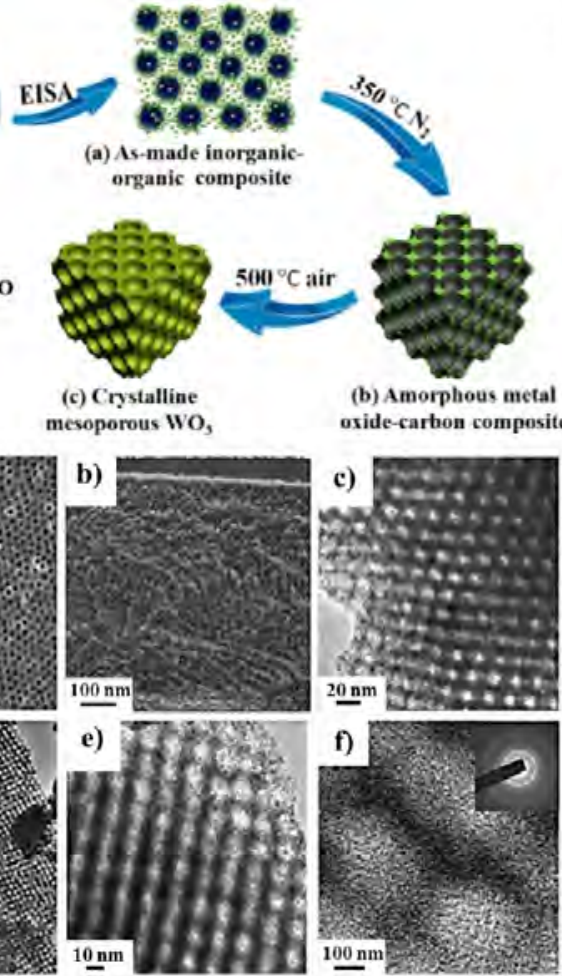

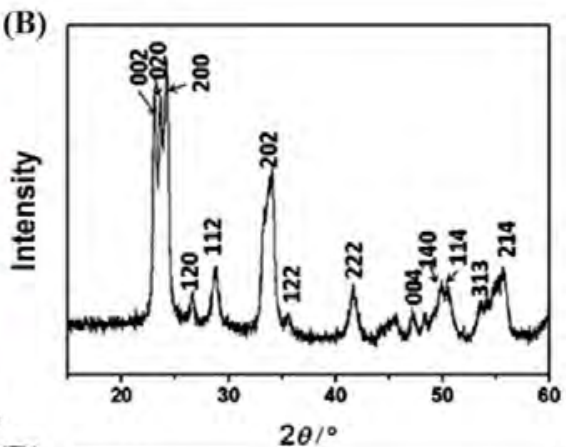

(D)

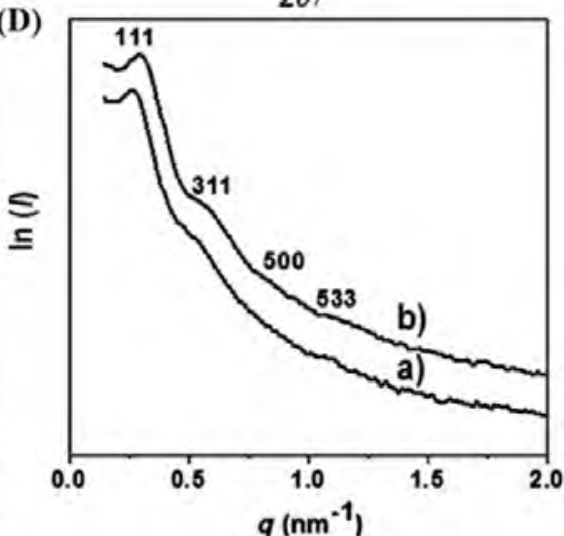

Figure 1. (A) The template-carbonization synthesis process of crystalline mesoporous $\mathrm{WO}_{3}$. (B) $\mathrm{XRD}$ pattern of the ordered crystalline mesoporous $\mathrm{WO}_{3}$. (C) FESEM images: (a) surface, (b) cross-section; TEM images taken along the (c) [110], (d) [100], (e) [211], and (f) HRTEM image of the crystalline ordered mesoporous $\mathrm{WO}_{3}$. (D) SAXS patterns of the ordered mesoporous $\mathrm{WO}_{3}$, (a) as-made and (b) after calcination at $500{ }^{\circ} \mathrm{C}$ in air. Adapted with permission from ref 31 . Copyright 2014 John Wiley and Sons.

system by virtue of the interface interaction between organic templates and inorganic precursor of metal oxides. With the reduction of the solubility of copolymers with associated inorganic species in the solution induced by various factors (e.g., the decreased content of good solvent, the increased content of nonsoluble inorganic species as a result of hydrolysis and condensation, etc), organic-inorganic micelles occur in two-phase interfaces. Subsequently, when the volatile solvent evaporates completely, preformed mesoscopic liquid-crystal phase is closely packed, forming nanocomposites with specific ordered mesostructures. As a result of the structural supporting of the residual carbon generated by pyrolysis of the $\mathrm{sp}^{2}$ hybridized carbon-containing block copolymers, OMSMOs can be obtained without structure collapse.

\subsection{Direct Interfacial Coassembly}

On the basis of typical EICA method, OMSMOs can be synthesized directly via a direct template-carbonization strategy. For instance, adopting lab-made $\mathrm{PEO}_{117}-b$ - $\mathrm{PS}_{198}$ with high molecular weight ( $\mathrm{ca} .25850 \mathrm{~g} \cdot \mathrm{mol}^{-1}$ ) as a soft template, ordered mesoporous $\mathrm{WO}_{3}$ was fabricated for the first time through direct EICA strategy based on the strong interaction between the PEO segments of $\mathrm{PEO}_{117}-b-\mathrm{PS}_{198}$ and $\mathrm{W}^{6+}$ species, as shown in Figure $1 \mathrm{~A} .{ }^{31}$ With the evaporation of THF, closely packed spherical micelles with hydrophobic PS core and hydrophilic PEOtungsten species form stable ordered mesostructures via strong hydrogen bonds. The carbonization of PS segments can in situ generate stable residual carbon in mesopores, which supports the ordered inorganic framework converting into crystalline $\mathrm{WO}_{3}$ in high-temperature treatment, ensuring a large mesopore size $(\sim 10.9 \mathrm{~nm})$ and high surface area $\left(\sim 121 \mathrm{~m}^{2} \cdot \mathrm{g}^{-1}\right)$. The results of X-ray diffraction (XRD; Figure $1 \mathrm{~B})$ showed typical crystalline monoclinic phase of $\mathrm{WO}_{3}$, which exhibited strong diffraction peaks and high crystallization. According to the scanning/transmission electron microscopy (SEM/TEM) images (Figure 1C) and small-angle X-ray scattering (SAXS) spectra (Figure 1D), the obtained mesoporous $\mathrm{WO}_{3}$ has facecentered cubic (fcc) (space group: $F m 3 m$ ) mesostructure. Similarly, PEO- $b$-PS copolymers can directly interact and coassemble with indium chloride to form ordered mesostructures. To avoid the mesostructure collapse during the simultaneous process of framework crystallization and template removal, $\mathrm{CaO}_{2}$ powder was used to promote the combustion of organic template during calcination via the burst release abundant oxygen, and ordered mesoporous $\operatorname{In}_{2} \mathrm{O}_{3}$ with large uniform pore size $(\sim 14.5 \mathrm{~nm})$ and highly crystalline nanosheetassembled framework was obtained via short-time calcination $(30 \mathrm{~min})$ at relatively lower temperature $\left(400{ }^{\circ} \mathrm{C}\right) .^{32}$

Besides PEO- $b$-PS, PS- $b$-P4VP copolymers were also designed and used as template to directly assemble with inorganic precursors. ${ }^{33-35}$ In this case, by using the electrostatic interactions between the protonated P4VP segments and the hydrolyzed titanium tetrabutoxide in acidic THF solution, ordered mesoporous titania with in situ $\mathrm{N}$-doped crystalline anatase framework has been synthesized by using P4VP as the nitrogen source. ${ }^{33}$ By contrast, because of the limitation of the weak interaction between late transition-metal precursors and block copolymers, other common metal oxides with low crystallization temperature, including $\mathrm{ZnO}, \mathrm{Co}_{3} \mathrm{O}_{4}, \mathrm{Fe}_{2} \mathrm{O}_{3}$, etc., are difficult to synthesize through the simple direct coassembly strategy. To solve the key issue of weak interactions, our group developed a series of techniques to strengthen the 

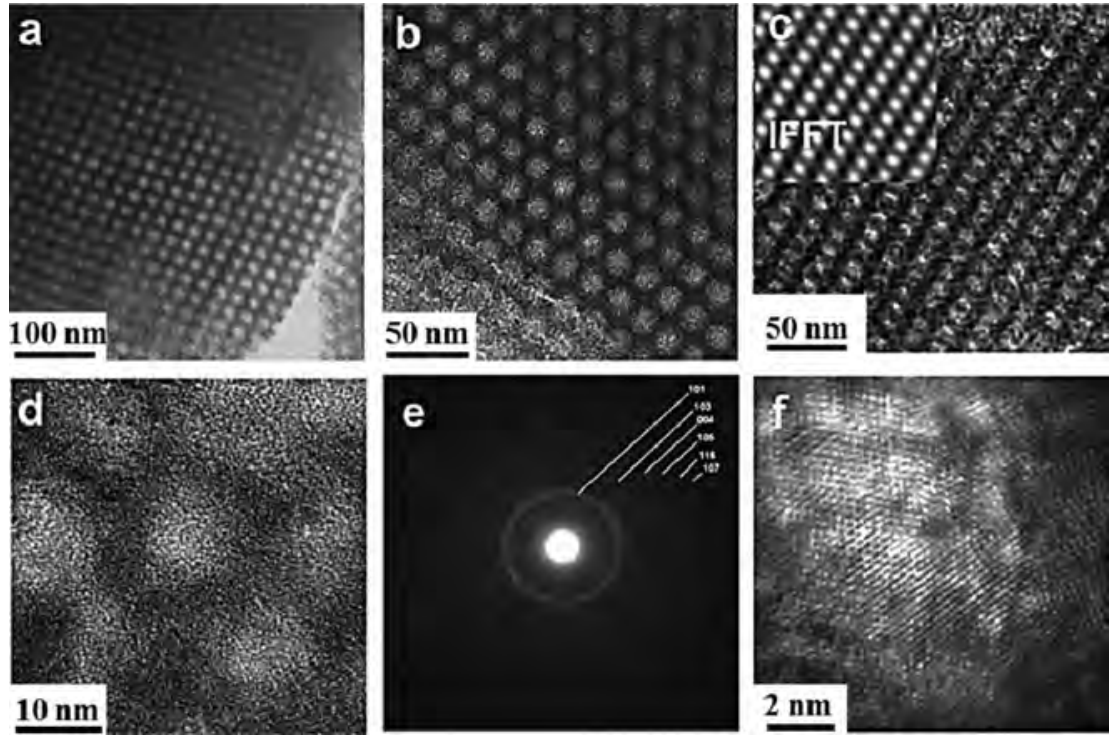

Figure 2. TEM images of the large-pore mesoporous titania MPTi-600N viewed from (a) [100], (b, d) [111], and (c) [210] directions. HRTEM images $(\mathrm{d}, \mathrm{f})$ of ordered mesoporous titania MPTi-600N, (e) is the corresponding SAED pattern from (c), exhibiting diffraction rings indexed to anatase phase. Adapted with permission from ref 36. Copyright 2011 John Wiley and Sons.

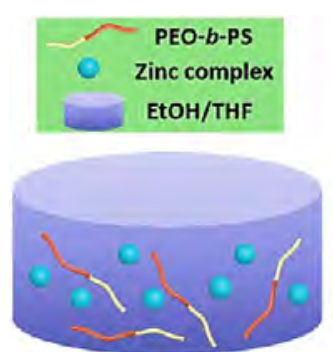

(a) Precursor solution

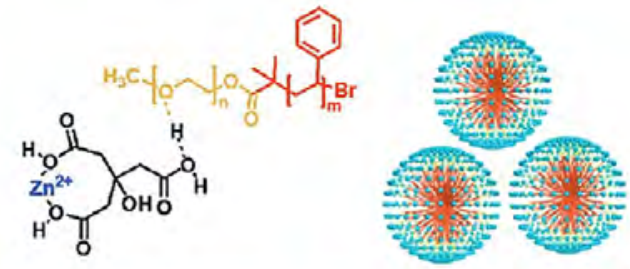

STEP 1

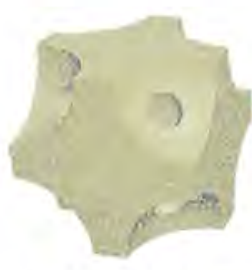

(d) PEO-b-PS/Zn-400

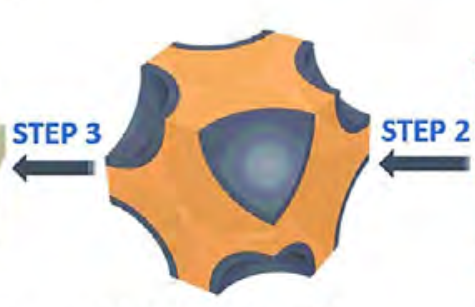

(c) PEO-b-PS/Zn-250

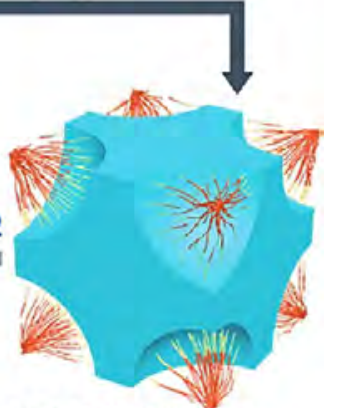

(b) PEO-b-PS/Zn-100

Figure 3. Chelation-assisted synthesis process of crystalline mesoporous $\mathrm{ZnO}$. Adapted with permission from ref 42 . Copyright $2016 \mathrm{Royal}$ Society of Chemistry.

interaction between precursors and template molecules, including ligand-assisted and resol-assisted strategies.

\subsection{Ligand-Assisted Assembly Strategy}

In the synthesis of inorganic nanomaterials like nanocrystals, various ligands with different functional groups (thiol, carboxyl, amino), have been frequently employed to suppress the growth of nanoparticles into large ones or to achieve a controllable synthesis in terms of shape and morphology by using their strong ability to bind metal atoms. For the synthesis of mesoporous materials based on the soft-templating method, a ligand with multiple functional groups as an efficient "bridge" can not only reduce the hydrolysis and condensation rate of precursors of metal oxides but also facilitate the organic/inorganic coassembly process through interaction with PEO segments via hydrogen bonds and simultaneous coordination bonding with metal ions.
Early in 2011, we for the first time studied large-pore mesoporous $\mathrm{TiO}_{2}$ with attractive crystalline framework via a novel ligand-assisted assembly strategy based on copolymer $\mathrm{PEO}_{125}-b-\mathrm{PS}_{130}$ as a template. Acetylacetone (AcAc) was used as the crucial coordination agent to retard the hydrolysis and condensation of Ti precursor (titanium isopropoxide (TIPO)) and avoid the phase separation of organic and inorganic species in the acidic THF solution. ${ }^{36}$ As shown in Figure 2, the obtained titania materials exhibited ordered mesoporous framework, and the pore wall was composed of anatase nanocrystals. Thereafter, much effort has been devoted to design ordered mesoporous $\mathrm{TiO}_{2}$ using various precursors, such as titanium alkoxide $\left[\mathrm{Ti}(\mathrm{OR})_{4}\right]$, soluble peroxytitanate $\left[\mathrm{TiO}_{2}(\mathrm{OH})\left(\mathrm{H}_{2} \mathrm{O}\right)\right] \mathrm{OH}$, titanium tetrachloride $\left(\mathrm{TiCl}_{4}\right)$, and tetrabutyl titanate (TBOT). Except for pure mesoporous $\mathrm{TiO}_{2}$, element-doped $\left(\mathrm{Cu}^{2+}\right.$ and $\left.\mathrm{Mn}^{4+}\right)$ and organic-inorganic hybrid materials of $\mathrm{g}$ - 
$\mathrm{C}_{3} \mathrm{~N}_{4}$ and mesoporous $\mathrm{TiO}_{2}$ have also been synthesized using acetic acid-assisted and $p$-hydroxybenzonic acid assisted EICA strategy, respectively. ${ }^{37,38}$

Recently, with the assistance of $\mathrm{HCl}$-AcAc dual-ligand, ordered mesoporous crystalline $\mathrm{SnO}_{2}$ can be obtained via classic EICA method with robust PEO- $b$-PS copolymer directed coassembly. ${ }^{39}$ The acetylacetone-stabilized inorganic species were found to be ultrafine $\mathrm{SnO}_{2}$ nanoclusters (ca. $2.5 \mathrm{~nm}$ ), because the $\mathrm{SnCl}_{4}$ precursor could be hydrolyzed even in the presence of trace water in THF. These $\mathrm{SnO}_{2}$ nanoclusters can coassemble with $\mathrm{PEO}_{114}-b-\mathrm{PS}_{248}$ to form uniform spherical micelles via strong hydrogen bonds. Although ordered mesoporous $\mathrm{WO}_{3}$ can be obtained through the direct EICA technique by carefully controlling the conditions (humidity, THF evaporation speed, precursor concentration, etc.), the textural parameters (e.g., pore dimension, wall thickness, porosity) are difficult to regulate, and the introduction of extra functional compositions (e.g., $\mathrm{Pt}, \mathrm{Au}, \mathrm{Pd}$ precursors) can interfere with the coassembly of $\mathrm{WCl}_{6}$ with $\mathrm{PEO}-b$-PS copolymers. Thus, the AcAc-assisted assembly method was extended to synthesize mesoporous $\mathrm{WO}_{3}$, allowing for a highly reproducible, reliable, and scalable production of high-quality mesoporous $\mathrm{WO}_{3}$ within a large synthesis window due to the complexation of AcAc with $\mathrm{WCl}_{6}$ to form $\mathrm{WCl}_{6-x}(\mathrm{AcAc})_{x}$. With this method, a series of lab-made PEO-b-PS copolymers with various molecular weights can be used for the controllable templating synthesis of crystalline ordered mesoporous $\mathrm{WO}_{3}$ with different pore sizes, ${ }^{40}$ and more importantly, hydrophobic (1,5-cyclooctadiene) dimethylplatinum(II) (i.e., Pt precursor) can be introduced in the synthesis system, leading to $\mathrm{Pt}$ nanoparticles sensitized ordered mesoporous $\mathrm{WO}_{3}{ }^{41}$

By contrast, $\mathrm{ZnO}$ has a lower crystallization temperature $\left(200-400^{\circ} \mathrm{C}\right)$, and due to the weak interaction between its salts and amphiphilic block copolymers, it maintains a great challenge to obtain ordered mesoporous structures. Citric acid as powerful chelating agent was recently found to be able to enhance the interaction between PEO- $b$-PS and $\mathrm{Zn}\left(\mathrm{NO}_{3}\right)_{2} \cdot 6 \mathrm{H}_{2} \mathrm{O}$ via hydrogen bonds, that is, $\mathrm{Zn}^{2+}-\mathrm{O}-\mathrm{C}-\mathrm{O} \cdots \cdot \mathrm{H}^{+} \cdots \mathrm{EO}$ (Figure $3) .{ }^{42}$ Interestingly, in addition to the large mesopores $(29.0 \mathrm{~nm})$ generated by the block copolymers, numerous small mesopores (3.2 $\mathrm{nm}$ ) were formed in the pore walls due to the decomposition of $\mathrm{ZnCO}_{3}$ intermediate and the random packing of the resultant $\mathrm{ZnO}$ nanoparticles during thermal treatment. The ligand-assisted coassembly strategy can enhance the inorganic-organic interaction, avoid incompatibility among components in assembly system, and thus hold a great promise for controllable synthesis of functional semiconducitng metal oxides with ordered mesoporosity and multicomponents.

\subsection{Resol-Assisted Coassembly Strategy}

In fact, except for ligand-assisted strategy based on various chelating agents, our group developed a general resol-assisted coassembly by utilization of the multiple phenolic hydroxyl groups of resol with complex transition-metal oxide precursors. Resol is a soluble macromolecule synthesized by condensation polymerization of phenol and formaldehyde in alkaline solutions. Resol can simultaneously interact with hydrophilic blocks of PEO-b-PS (P4VP-b-PS) and transition-metal salts, enabling an effective multicomponent coassembly into ordered mesostructures. During pyrolysis in inert atmospheres, the residual carbon derived from both resol and template molecules can support the crystallization of metal oxides, forming mesoporous carbon-metal oxide nanocomposites, ${ }^{43}$ and upon calcination in air, mesoporous carbon-metal oxide nanocomposites can be converted into mesoporous metal oxides which provide that metal oxides have a high content in the nanocomposites. ${ }^{44}$ For example, by using resol as a robust bridge that connects $\mathrm{PEO}$ segments through hydrogen bonds and meanwhile complex $\mathrm{Co}^{2+}$ ions via coordination interactions, ordered mesoporous carbon-cobalt oxide hybrid materials with large pore size (13.4-16.0 nm) and high surface area (394-483 $\mathrm{m}^{2} \cdot \mathrm{g}^{-1}$ ) were synthesized (Figure 4$){ }^{43}$ Similarly, crystalline mesoporous $\mathrm{Nb}_{2} \mathrm{O}_{5}$ spheres were synthesized after sequential pyrolysis and calcination using $\mathrm{NbCl}_{5}$ precursor (Figure 5). ${ }^{44}$ The obtained mesoporous $\mathrm{Nb}_{2} \mathrm{O}_{5}$ spheres have large pore size $(\sim 11.4 \mathrm{~nm})$, high surface area $\left(131 \mathrm{~m}^{2} \cdot \mathrm{g}^{-1}\right)$, and highly crystalline framework. As shown in Figure 5, PEO-b-PS copolymers could form rodlike micelles as the fast evaporation of THF, and hydrophilic resol as the sacrificial carbon source

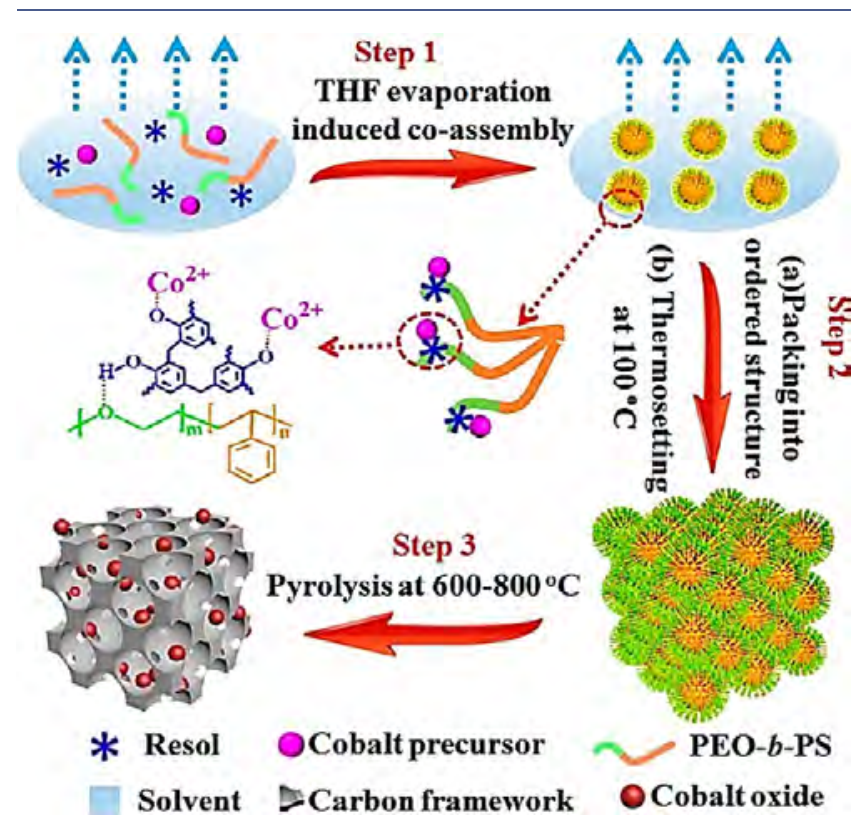

Figure 4. Formation process of ordered mesoporous $\mathrm{CoO}_{x} / \mathrm{C}$ nanocomposites with large mesopores and graphitic walls. Adapted with permission from ref 43. Copyright 2016 American Chemical Society.

could interact preferentially with PEO and served as a glue to bridge the metal species and block copolymers. Furthermore, by changing the relative amount of resol, dual mesoporous metal oxides with tunable pore size and window size can be readily synthesized. ${ }^{45}$ Thus, this resol-assisted coassembly strategy can efficiently enhance the interaction between copolymers and metal precursors whose hydrolysis and condensation are difficult to control.

Thus, the available ligand or auxiliary components can adjust flexibly the interaction between block copolymers and target metal precursors. Moreover, these ligands can also chelate or complex with metal species to form stable ordered mesoporous framework by controlling the kinetic hydrolysis behavior. More novel OMSMOs with crystalline framework, diverse compositions, and pore structures can be created for applications in multidisciplinary fields. 


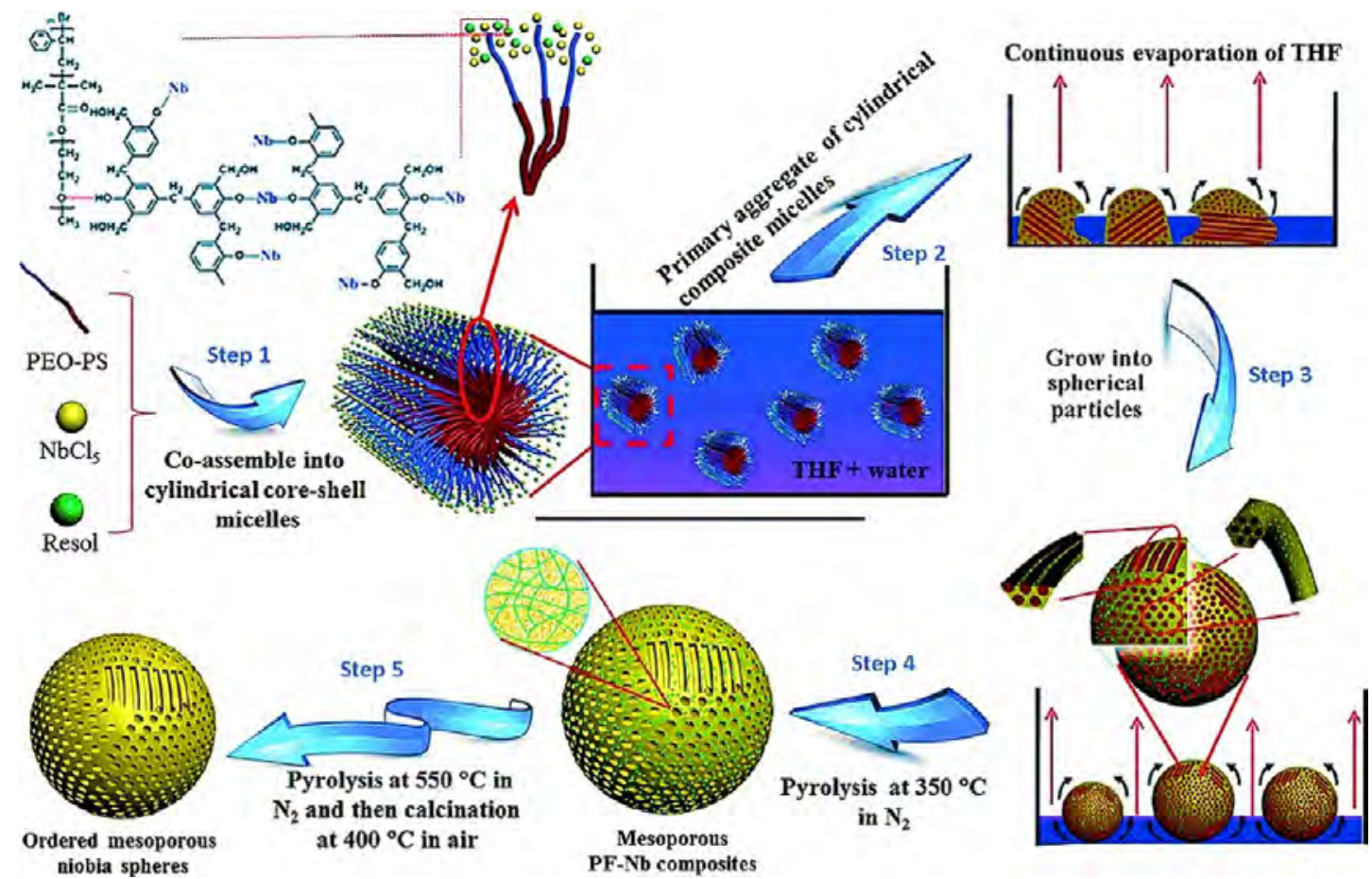

Figure 5. Formation process of the ordered mesoporous $\mathrm{Nb}_{2} \mathrm{O}_{5}$ spheres by the resol-assisted EICA approach. Adapted with permission from ref 44 . Copyright 2013 John Wiley and Sons.

\section{GAS-SENSING APPLICATIONS OF OMSMOS}

\subsection{Gas-Sensing Performance}

Chemiresistive gas sensor is one of the most important techniques for the real-time monitor and detection of toxic gas and flammable or explosive gas, which is crucial to public healthcare and environmental safety. Semiconducting metal oxides have been considered as ideal candidates, as the sensing layers for fabrication of high-performance gas sensor based on their dramatic resistance change upon contact target gases. The resistance of these materials may increase or decrease owing to their inherent physicochemical property and variable conductivity in atmosphere of reducing or oxidizing analytes (e.g., $\mathrm{H}_{2} \mathrm{~S}, \mathrm{CO}, \mathrm{NO}_{x}$, alcohol, aldehyde, and low-molecular weight alkane and aromatic compounds). According to the variation of current carrier and sensing mechanism, semiconducting metal oxides can be divided into two typical categories, namely, n-type (e.g., $\mathrm{WO}_{3}, \mathrm{In}_{2} \mathrm{O}_{3}, \mathrm{SnO}_{2}$, etc.) and p-type (e.g., $\mathrm{NiO}, \mathrm{CuO}$, $\mathrm{Co}_{3} \mathrm{O}_{4}$, etc.). To evaluate the sensing efficiency, five main indicators have been adopted and used in practical applications including detection temperature, response sensitivity (gas response $(S)=R_{\mathrm{a}} / R_{\mathrm{g}}$, where $R_{\mathrm{a}}$ and $R_{\mathrm{g}}$ refer to the resistance in air and target gas, respectively), response/recovery time, selectivity, and stability. The performance of semiconducting metal oxides usually depends on the nature of sensing materials, including porosity, surface area, crystallinity, interface effect, grain size, etc. Thus, exploring and designing functional metal oxides with high activity and unique microstructure is essential for the enhancement of sensing performance.

Typical gas-sensor nanodevice is shown in Figure 6a-c; the mesoporous $\mathrm{ZnO}$ powder was dispersed in deionized water to form a homogeneous paste, which was coated on alumina ceramic tube twined with Au electrodes, and a $\mathrm{Ni}-\mathrm{Cr}$ alloy wire was then inserted into the tube as a heater. On the basis of the assynthesized ordered mesoporous $\mathrm{ZnO}$ materials, the nano- devices showed superior sensing performance to ethanol with a fast response and recovery time $(6 / 7 \mathrm{~s})$ due to the unique hierarchical mesopores and crystalline framework of $\mathrm{ZnO}$ materials. Especially, compared with $\mathrm{ZnO}$ sensors with other nanostructures, including nanosheet, nanowires, nanodisks, nanostars, nanorods, microspheres, flakes, etc., the ordered mesoporous $\mathrm{ZnO}$ sensors showed superior sensing properties to ethanol. ${ }^{42}$ Similarly, ordered mesoporous $\mathrm{In}_{2} \mathrm{O}_{3}$ exhibited high response values (10.5) to oxidative $\mathrm{NO}_{2}$, one of the main culprits of air pollution, at low temperature of $150{ }^{\circ} \mathrm{C}$ even in concentration as low as $250 \mathrm{ppb}$ (Figure $6 \mathrm{~d}-\mathrm{f}$ ) because of their unique nanosheets-assembled pore wall and abundantly exposed active sites. The ordered mesoporous structure shows excellent performance to $\mathrm{NO}_{2}$ compared with nonporous structure, such as nanowires, spheres, and nanoparticles, revealing the tremendous advantages of mesoporous structure in gas sensing. ${ }^{32}$ Very recently, mesoporous $\mathrm{In}_{2} \mathrm{O}_{3}$ modified with highly dispersed $\mathrm{Pd}$ nanodots were synthesized, which exhibited high response to $\mathrm{H}_{2}$ even in the low concentration range of $0.5-$ 100 ppm. ${ }^{46}$ Crystalline mesoporous $\mathrm{WO}_{3}$ materials exhibit attractive sensing performance to $\mathrm{H}_{2} \mathrm{~S}$ at low concentration $(0.25 \mathrm{ppm})$ with fast response of $2 \mathrm{~s}$ and recovery of $38 \mathrm{~s}$ (Figure $6 \mathrm{~g}, \mathrm{~h}) .{ }^{31}$ Moreover, they show selective response to $\mathrm{H}_{2} \mathrm{~S}$, with a large response value of at least 6 times higher than those of interfering gases (Figure 6i). Compared with n-type metal oxides, p-type ones show relatively low response and selectivity because of their weak electrical conductivity. To address this problem, ordered mesoporous $\mathrm{CoO}_{x} / \mathrm{C}$ composites with large pores and good electric conductivity of graphitic carbon matrix were recently designed, which showed superior response to $\mathrm{H}_{2}$ at a concentration of $0.25 \%{ }^{43}$

Besides the composition and crystalline framework, other key factors (e.g., porosity, active sites, surface defects) can also affect the gas sensing performance of OMSMOs. Through changing the molecule weight and the PS chain length of PEO-b-PS 
(a)

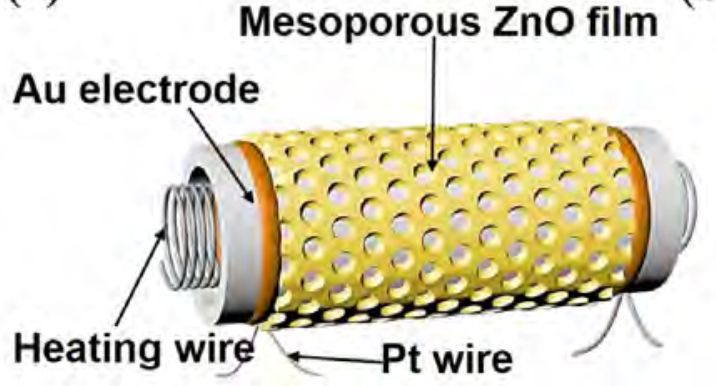

(b)

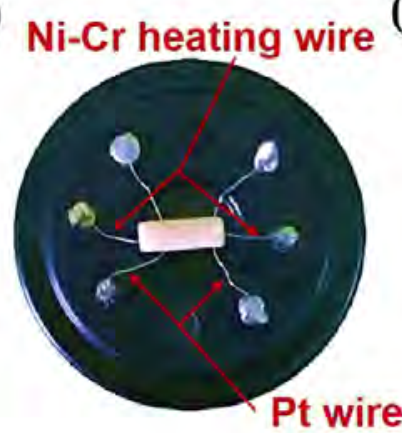

(c)

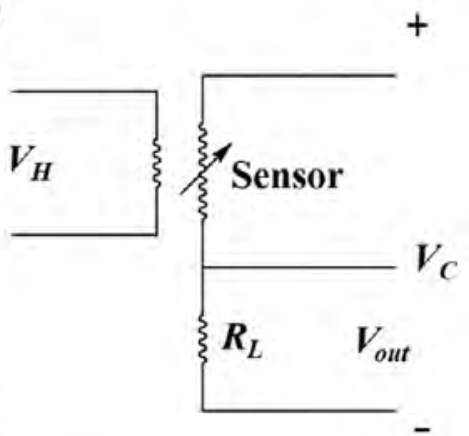

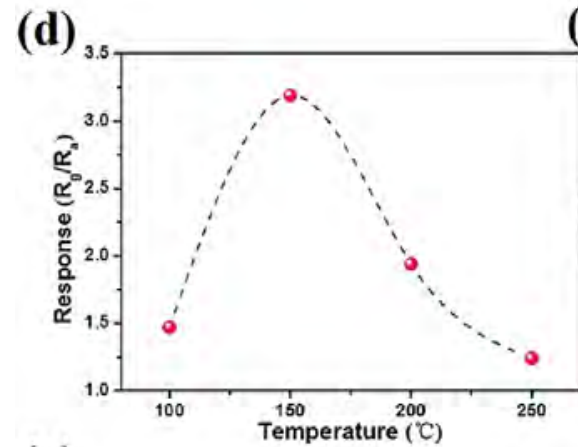

(g)

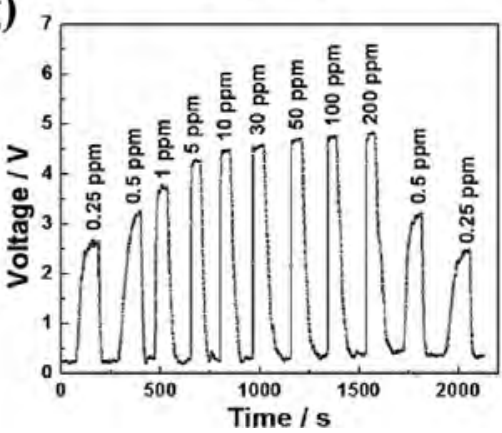

(e)

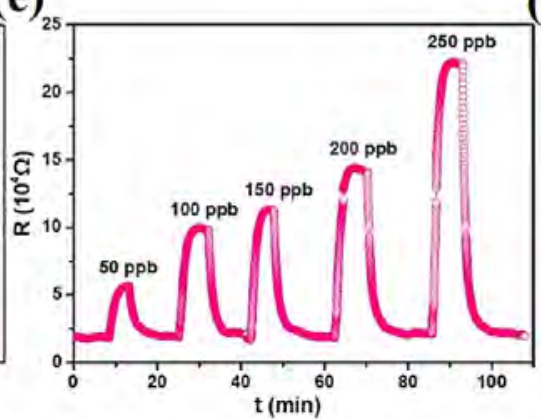

(h)

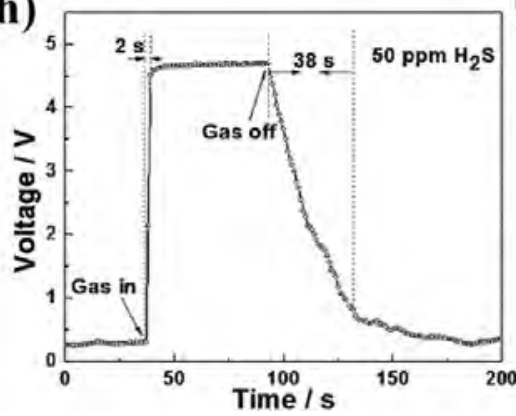

(f)

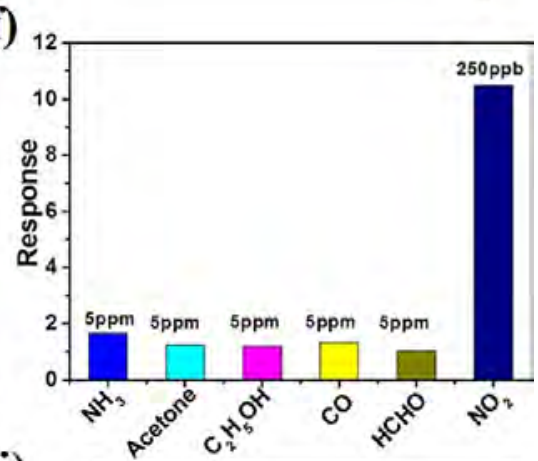

(i)

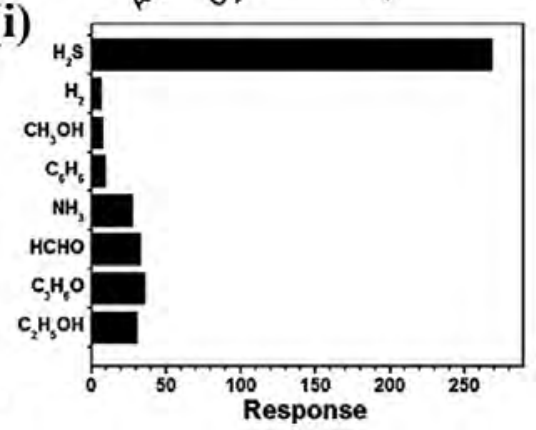

Figure 6. (a) Photo of the assembled device. (b) The electric circuit of gas sensing measurements. (c) Sketch of the structure of the side-heated mesoporous $\mathrm{ZnO}$-based gas sensor. Adopted with permission from ref 42. Copyright 2016 Royal Society of Chemistry. (d-f) The response of mesoporous $\mathrm{In}_{2} \mathrm{O}_{3}$-based sensor to $\mathrm{NO}_{2}$. Adopted with permission from ref 32. Copyright 2016 American Chemical Society. ( $\left.\mathrm{g}-\mathrm{i}\right)$ The response of the crystalline mesoporous $\mathrm{WO}_{3}$ sensor to $\mathrm{H}_{2} \mathrm{~S}$. Adapted with permission from ref 31. Copyright 2014 John Wiley and Sons.

copolymers, the pore size and specific surface area of the obtained ordered mesoporous $\mathrm{WO}_{3}$ can be readily adjusted. ${ }^{40}$ Four groups of gas sensors with different surface areas were fabricated by using mesoporous $\mathrm{WO}_{3}$ from templates of different molecular weights (Table 1). The sensors demonstrated high sensitivity and selectivity to low-concentration 3hydroxy-2-butanone, a typical biomarker of exhaled gas from Listeria monocytogenes, and their response increases with increasing surface area. Because of their high surface area, uniform pore size, and rich exposed sites, these ordered mesoporous $\mathrm{WO}_{3}$ showed $\sim 5-10$ times higher sensitivity than that of commercial $\mathrm{WO}_{3}$ nanoparticles, making it possible to monitor the microbial contamination of food indirectly by measuring biomarker of exhaled gas from Listeria monocytogenes (Figure 7).

It is worth noting that, because of the large pore size, the OMSMOs allow for in-pore deposition of foreigner nanoparticles (e.g., Pt, Pd, $\mathrm{Au}$ ) without blocking pore channels, which provides numerous active metal oxide-metal interfaces to catalyze the reaction of target gases, leading to improved gas sensing performance with lower working temperature and better selectivity or sensitivity. ${ }^{41,46}$
Table 1. Texture Properties and Sensing Performance of the Obtained $\mathrm{WO}_{3}-\mathrm{PEO}_{x}-b-\mathrm{PS}_{y}$ and Commercial $\mathrm{WO}_{3}$ Particles $^{40}$

\begin{tabular}{|c|c|c|c|c|c|}
\hline samples & $\begin{array}{l}\text { BET } \\
\text { surface } \\
\text { area } \\
\left(\mathrm{m}^{2} / \mathrm{g}\right)\end{array}$ & $\begin{array}{l}\text { total pore } \\
\text { volume } \\
\left(\mathrm{cm}^{3} / \mathrm{g}\right)\end{array}$ & $\begin{array}{l}\text { pore } \\
\text { size } \\
(\mathrm{nm})\end{array}$ & $\begin{array}{l}\text { sensitivity } \\
\left(R_{\mathrm{a}} / R_{\mathrm{g}}\right)\end{array}$ & $\begin{array}{c}\text { response/ } \\
\text { recovery } \\
\text { (s) }\end{array}$ \\
\hline $\begin{array}{l}\text { commercial } \\
\mathrm{WO}_{3}\end{array}$ & 6 & & & 6.2 & $18.0 / 43.0$ \\
\hline $\begin{array}{l}\mathrm{WO}_{3}- \\
\mathrm{PEO}_{117}-b- \\
\mathrm{PS}_{297}\end{array}$ & 76 & 0.17 & 15.3 & 32.7 & $12.0 / 30.0$ \\
\hline $\begin{array}{l}\mathrm{WO}_{3}- \\
\mathrm{PEO}_{117}-b- \\
\mathrm{PS}_{232}\end{array}$ & 95 & 0.15 & 12.1 & 46.2 & $10.0 / 26.0$ \\
\hline $\begin{array}{l}\mathrm{WO}_{3}- \\
\mathrm{PEO}_{117}-b- \\
\mathrm{PS}_{186}\end{array}$ & 136 & 0.13 & 10.6 & 56.1 & $4.0 / 13.0$ \\
\hline
\end{tabular}

\subsection{Gas-Sensing Mechanism}

In general, the current carrier of n-type semiconductor is electrons, and adsorbed oxygen molecules tend to capture electrons from the surface of metal oxides to produce abundant active oxygen species (e.g., $\mathrm{O}^{2-}$ and $\mathrm{O}^{-}$), which can reduce the 

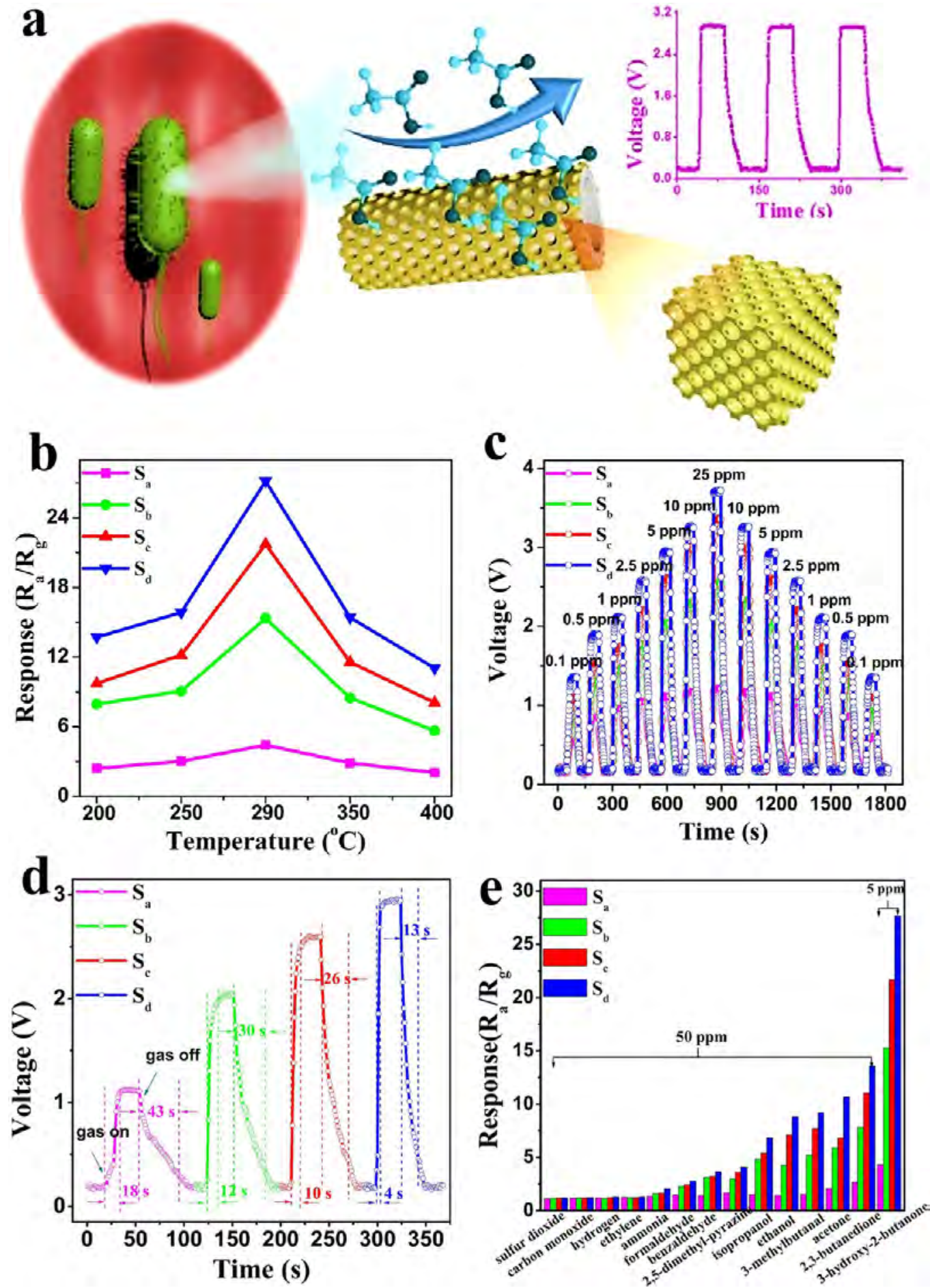

Figure 7. (a) The principle for detection of Listeria monocytogenes using the sensor-based $\mathrm{WO}_{3}-\mathrm{PEO}_{117}-b$ - $\mathrm{PS}_{186}$. $(\mathrm{b}-\mathrm{e}$ ) The responses of the sensors base on 3-hydroxy-2-butanone $\left(S_{a}, S_{\mathrm{b}}, S_{\mathcal{c}}\right.$, and $S_{\mathrm{d}}$ based on commercial $\mathrm{WO}_{3}$ particles, $\mathrm{WO}_{3}-\mathrm{PEO}_{117}-b-\mathrm{PS}_{297}, \mathrm{WO}_{3}-\mathrm{PEO}_{117}-b-\mathrm{PS}_{232}$, and $\mathrm{WO}_{3}-$ $\mathrm{PEO}_{117}-b-\mathrm{PS}_{186}$, respectively). Adapted with permission from ref 40. Copyright 2017 American Chemical Society.

electron density and increase the resistance of metal oxides. In addition, the surface charge density is dependent on the surfacelimited depth derived from these active oxygen species, and the affected region usually endows low electron density, which defines the depletion layer. On the basis of the depletion layer, once n-type semiconducting metal oxides contact reducing gases (e.g., CO, ethanol, and acetone), electrons return to the sensing layer, inducing the rapid decrease of resistance. In the opposite, exposure to oxidizing components (e.g., $\mathrm{Cl}_{2}, \mathrm{NO}_{x}, \mathrm{SO}_{2}$ ) can intensify the electron depletion and result in increasing resistance of metal oxides. By contrast, p-type semiconductors possess distinct sensing mechanism, the effective holes $\left(h^{+}\right)$as current carrier endowed inversed response of resistance when exposed in reducing or oxidizing gases.

Our group performed a series of investigations about the gas sensing mechanism of the $\mathrm{sp}^{2}$-carbon containing copolymers templated OMSMOs. For example, the sensing process of ntype mesoporous $\mathrm{WO}_{3}$ complies with the surface-depletion 


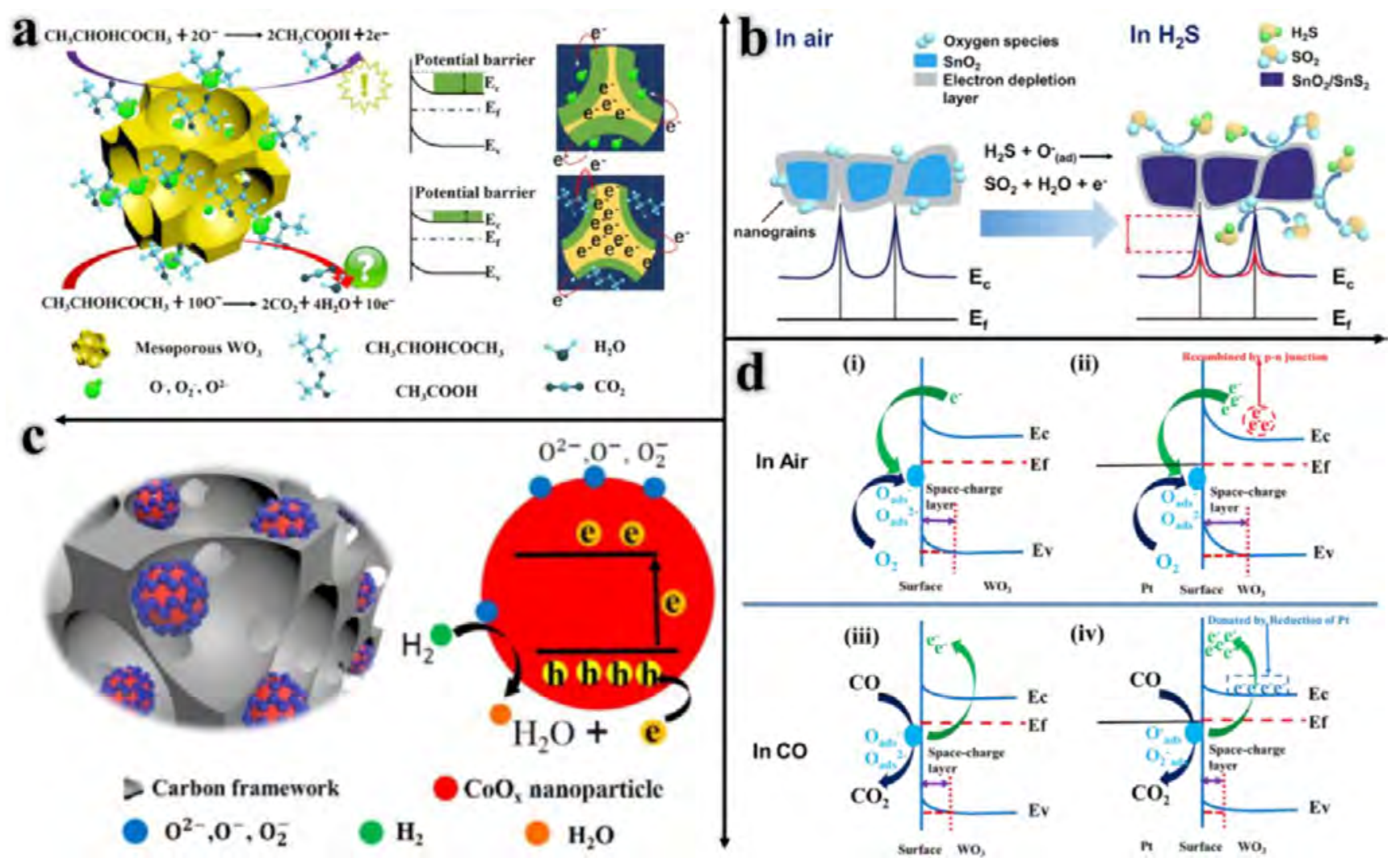

Figure 8. (a) 3-Hydroxy-2-butanone sensing mechanism of the sensors based on n-type mesoporous $\mathrm{WO}_{3}$ material. $\left(E_{\mathrm{v}}=\right.$ valence band edge; $E_{\mathrm{c}}=$ conduction band edge; $E_{\mathrm{f}}=$ Fermi energy). Adapted with permission from ref 40. Copyright 2017 American Chemical Society. (b) $\mathrm{H}_{2} \mathrm{~S}$ sensing mechanism of the sensors based on mesoporous n-type $\mathrm{SnO}_{2}$ material. Adapted with permission from ref 39. Copyright 2018 American Chemical Society. (c) $\mathrm{H}_{2}$ sensing mechanism of the sensors based on mesoporous $p$-type $\mathrm{CoO}_{x} / \mathrm{C}$. Adapted with permission from ref 43 . Copyright 2016 American Chemical Society. (d) CO sensing mechanism of the sensors based on mesoporous $\mathrm{WO}_{3}$ exposed in air (i) and CO (iii), and Pt-doped ordered mesoporous $\mathrm{WO}_{3}$ exposed in air (ii) and $\mathrm{CO}$ (iv), respectively $\left(E_{\mathrm{v}}\right.$, valence band edge; $E_{\mathcal{C}}$ conduction band edge; $E_{\mathrm{f}}$, Fermi energy). Adapted with permission from ref 41 . Copyright 2017 John Wiley and Sons.

theory as follows. When they contact air (Figure 8a), ${ }^{40}$ oxygen molecules can adsorb on the pore wall surface of mesoporous $\mathrm{WO}_{3}$ to grasp electrons (conduction band) and produce abundant oxygen species. Consequently, the formed thick space-charge layer increases the potential barriers with a higher resistance, which accounts for the electrical resistance of metal oxides. In our recent research, we proved that the gas sensing behavior is dependent on the crystal size of metal oxides in the pore wall of OMSMOs (Figure $8 \mathrm{~b}$ ). ${ }^{39}$ In this regard, metal oxide homojunctions were generated between nanograins in the crystalline mesoporous framework, which could accelerate the diffusion of active oxygen species, and these oxygen species usually covered the surface of nanograins. It can capture electrons of these nanograins and generate electron depletion layer, generating potential barriers among the grain boundaries. Thus, the resistance of metal oxides can be adjusted through these potential barriers in target gases. In comparison, during the sensing process of p-type $\mathrm{Co}_{3} \mathrm{O}_{4}$, oxygen molecules can trap and react with electrons from conduction band of $\mathrm{CoO}_{x} / \mathrm{C}$ (Figure $8 \mathrm{c}),{ }^{43}$ forming the depletion layer consisting of negative oxygen species on the surface of $\mathrm{Co}_{3} \mathrm{O}_{4}$ nanoparticles. In the atmosphere of reducing $\mathrm{H}_{2}, \mathrm{H}_{2}$ molecules can react with these negative oxygen species to form $\mathrm{H}_{2} \mathrm{O}$, and electrons flow back to $\mathrm{Co}_{3} \mathrm{O}_{4}$ and recombine with hole to increase its resistance. Apart from n-type and p-type semiconductors, various heterojunctions, such as $\mathrm{p}-\mathrm{n}, \mathrm{n}-\mathrm{n}$ junctions, can significantly enhance chemical activity and sensing performance based on the strong synergistic effect. For example, Pt-doped ordered mesoporous $\mathrm{WO}_{3}$ can be regarded as an excellent gas sensor to $\mathrm{CO}$ (Figure $8 \mathrm{~d}) .{ }^{41} \mathrm{It}$ is not only attributed to the high active and sensitization of $\mathrm{Pt}$ nanoparticles highly dispersed in the mesoporous $\mathrm{WO}_{3}$ matrix but also formed p-n heterojunction at the surface/ interface among Pt NPs, $\mathrm{PtO}_{x}$, and $\mathrm{WO}_{3}$, which is beneficial for the efficient allocation of the surface depletion layer and electron depletion.

\section{CONCLUSION AND PERSPECTIVES}

In this Account, we elucidate recent advances in the synthesis of OMSMOs, especially transition-metal oxides, based on $\mathrm{sp}^{2}$ hybridized carbon-containing block copolymers through various coassembly strategies. On the basis of their intrinsic phaseseparation behavior and their interaction with inorganic precursors, various OMSMOs have been synthesized by virtue of the supporting effect of residual carbon derivated from the soft template during pyrolysis at high temperatures. Recent progress in the synthesis of OMSMOs, such as $\mathrm{WO}_{3}, \operatorname{In}_{2} \mathrm{O}_{3}$, $\mathrm{SnO}_{2}$, and $\mathrm{ZnO}$, has been in detail discussed, with emphasis on explaining the unique role of $\mathrm{sp}^{2}$-hybridized carbon-containing block copolymers in solving the bottlenecks in the synthesis of mesoporous metal oxides with high crystallization and ordered mesoporous structures.

Despite the current achievements in the synthesis and applications of OMSMOs, there are still considerable challenges and opportunities existing in this field. (1) Since the gas sensing 
performance of OMSMOs is directly determined by their pore characteristics including pore structure, pore size, composition, and thickness of pore walls, it is of great importance to widely explore the efficient structural regulation using various $\mathrm{sp}^{2}$ hybridized carbon-containing block copolymers. Larger pore is beneficial for the gas diffusion but usually leads to smaller surface area, and thin pore walls can enhance the changes of conductometric chemiresistance in gas sensing process but easily lead to structure collapse. Thus, rational regulation of connectivity of channels, pore size, and thickness of pore walls is meaningful for gas sensing through controlling the ratio and length of hydrophilic/hydrophobic segments. (2) Because doping materials with nonmetal components (e.g., N, C, S, P) or metal ions (e.g., $\mathrm{Ni}^{2+}, \mathrm{Fe}^{3+}, \mathrm{Cr}^{3+}, \mathrm{Ce}^{4+}$ ) can change energy band and adjust the electronic structure/resistance of OMSMOs, lattice doping or replacement of basal atoms is a promising approach for the design of multifunctional OMSMOs with improved performances in terms of sensitivity and selectivity. (3) Large mesoporous materials can provide abundant adsorption sites for the deposition of noble metals (e.g., $\mathrm{Au}, \mathrm{Ag}, \mathrm{Pt}$ ), and these loading active components can reduce the resistance and form heterojunction or Schottky barrier, which is beneficial for the gas sensing process at low working temperatures. (4) Considering that $\mathrm{p}-\mathrm{n}$ or $\mathrm{n}-\mathrm{n}$ heterojunction can significantly decrease the steric hindrance and transition distance of electron/hole, designing diverse OMSMOs with novel heterostructures is another important pathway to fabricate gas sensing materials with high sensitivity. (5) Amorphous components like $\mathrm{SiO}_{2}$ can not only prevent metal oxides from sintering to increase long-term stability but also regulate the adsorption/diffusion behavior of target gas species to adjust the selectivity of gas sensing. Through exploring new synthesis strategies based on the interfacial coassembly of $\mathrm{sp}^{2}$-hybridized carbon-containing amphiphilic copolymers, precursors of metal oxides and additives (doping elements, amorphous components, precious metals, etc.), the abovementioned OMSMOs with improved porous structure, multicomponents, and tailored surface property can be created to boost the development of gas sensing. Notably, the development of new OMSMOs is beneficial for their applications in gas sensing and other fields such as catalysis, environmental protection, energy conversion and storage, etc.

\section{AUTHOR INFORMATION}

\section{Corresponding Author}

*E-mail: yhdeng@fudan.edu.cn.

\section{ORCID $\odot$}

Yidong Zou: 0000-0002-3549-8430

Dongyuan Zhao: 0000-0001-8440-6902

Yonghui Deng: 0000-0002-0657-9397

Notes

The authors declare no competing financial interest.

\section{Biographies}

Yidong Zou obtained his M.E. from East China University of Technology and joined Prof. Xiangke Wang's research group at North China Electric Power University as a joint trained student for one and a half years. He is pursuing his Ph.D. under the supervision of Prof. Yonghui Deng at Fudan University. His research interests include the synthesis of ordered mesoporous metal oxides and their applications in catalysis, adsorption and chemical sensing.
Xinran Zhou obtained her B.S. from Fudan University. She is pursuing her Ph.D. under the supervision of Prof. Dongyuan Zhao and Prof. Yonghui Deng. Her research focuses on the synthesis of ordered mesoporous materials and their application in chemical sensing.

Yongheng Zhu is an associate Professor at Shanghai Ocean University and post-doctoral fellow in Fudan University with Prof. Yonghui Deng. His research interests include the synthesis of nanomaterials and their application in sensors.

Xiaowei Cheng received his B.S. (2003) and Ph.D. (2008) from Fudan University. From 2015, he worked as the associate professor in Department of Chemistry at Fudan University. His research interests include the rational design and application of novel heterogeneous catalysts and biosensor nanomaterials based on porous materials.

Dongyuan Zhao received his B.S. (1984) and Ph.D. (1990) from Jilin University. He carried out postdoctoral research at the Weizmann Institute of Science (1993-1994), University of Houston (1995-1996), and University of California at Santa Barbara (19961998). He was elected as an academician of the Chinese Academy of Science in 2007, and a member of The World Academy of Science (TWAS) in 2010. His research interests are focused on the interfacial assembly and macroscopic control of ordered mesoporous materials for applications in catalysis, energy, water purification and biomedicine.

Yonghui Deng received his B.S. from Nanchang University (2000) and $\mathrm{Ph}$.D. from Fudan University (2005). He worked as a postdoctoral fellow with Prof. Dongyuan Zhao in Fudan University (2005-2007) and visiting scholar with Prof. Peidong Yang at University of California, Berkeley (2009-2010), respectively. He was promoted as associate (2007) and full professor (2011) in Fudan University. His research interests include functional porous materials and their applications in adsorption, separation, catalysis and gas sensing, etc.

\section{ACKNOWLEDGMENTS}

This work supported by the NSF of China (21673048, 31701678, and 21875044), Key Basic Research Program of Science and Technology Commission of Shanghai Municipality (17JC1400100), China postdoctoral special fund (2018T110338), the State Key Basic Research Program of the PRC (2016YFA0204000) and Youth Top-notch Talent Support Program of China.

\section{REFERENCES}

(1) Li, X. L.; Wang, X. R.; Zhang, L.; Lee, S.; Dai, H. J. Chemically Derived, Ultrasmooth Graphene Nanoribbon Semiconductors. Science 2008, 319, 1229-1232.

(2) Liu, B.; Wu, C. H.; Miao, J. W.; Yang, P. D. All Inorganic Semiconductor Nanowire Mesh for Direct Solar Water Splitting. ACS Nano 2014, 8, 11739-11744.

(3) Singh, K.; Nowotny, J.; Thangadurai, V. Amphoteric Oxide Semiconductors for Energy Conversion Devices: A Tutorial Review. Chem. Soc. Rev. 2013, 42, 1961-1972.

(4) Kim, H. J.; Lee, J. H. Highly Sensitive and Selective Gas Sensors Using P-Type Oxide Semiconductors: Overview. Sens. Actuators, B 2014, 192, 607-627.

(5) Ren, Y.; Ma, Z.; Bruce, P. G. Ordered Mesoporous Metal Oxides: Synthesis and Applications. Chem. Soc. Rev. 2012, 41, 4909-4927.

(6) Wang, Y. Q.; Yang, C. M.; Schmidt, W.; Spliethoff, B.; Bill, E.; Schüth, F. Weakly Ferromagnetic Ordered Mesoporous $\mathrm{Co}_{3} \mathrm{O}_{4}$ Synthesized by Nanocasting from Vinyl-Functionalized Cubic Ia3d Mesoporous Silica. Adv. Mater. 2005, 17, 53-56.

(7) Bian, Z. F.; Zhu, J.; Wang, S. H.; Cao, Y.; Qian, X. F.; Li, H. X. SelfAssembly of Active $\mathrm{Bi}_{2} \mathrm{O}_{3} / \mathrm{TiO}_{2}$ Visible Photocatalyst with Ordered Mesoporous Structure and Highly Crystallized Anatase. J. Phys. Chem. C 2008, 112, 6258-6262. 
(8) Yang, P. D.; Zhao, D. Y.; Margolese, D. I.; Chmelka, D. F.; Stucky, G. D. Generalized Syntheses of Large-Pore Mesoporous Metal Oxides with Semicrystalline Frameworks. Nature 1998, 396, 152-155.

(9) Li, W.; Yue, Q.; Deng, Y. H.; Zhao, D. Y. Ordered Mesoporous Materials Based on Interfacial Assembly and Engineering. Adv. Mater. 2013, 25, 5129-5152.

(10) Poyraz, A. S.; Kuo, C.; Biswas, S.; King'ondu, C. K.; Suib, S. L. A General Approach to Crystalline and Monomodal Pore Size Mesoporous Materials. Nat. Commun. 2013, 4, 2952.

(11) Wei, J.; Liu, Y. Y.; Chen, J.; Li, Y. H.; Yue, Q.; Pan, G. X.; Yu, Y. L.; Deng, Y. H.; Zhao, D. Y. Azobenzene-Derived Surfactants as Phototriggered Recyclable Templates for the Synthesis of Ordered Mesoporous Silica Nanospheres. Adv. Mater. 2014, 26, 1782-1787.

(12) Gao, W. J.; Wan, Y.; Dou, Y. Q.; Zhao, D. Y. Synthesis of Partially Graphitic Ordered Mesoporous Carbons with High Surface Areas. Adv. Energy Mater. 2011, 1, 115-123.

(13) Xue, C. F.; Tu, B.; Zhao, D. Y. Evaporation-Induced Coating and Self-Assembly of Ordered Mesoporous Carbon-Silica Composite Monoliths with Macroporous Architecture on Polyurethane Foams. Adv. Funct. Mater. 2008, 18, 3914-3921.

(14) Fang, Y.; Gu, D.; Zou, Y.; Wu, Z. X.; Li, F. Y.; Che, R. C.; Deng, Y. H.; Tu, B.; Zhao, D. Y. A Low-Concentration Hydrothermal Synthesis of Biocompatible Ordered Mesoporous Carbon Nanospheres with Tunable and Uniform Size. Angew. Chem., Int. Ed. 2010, 49, 79877991.

(15) Grewe, T.; Deng, X. H.; Weidenthaler, C.; Schüth, F.; Tüysüz, H. Design of Ordered Mesoporous Composite Materials and Their Electrocatalytic Activities for Water Oxidation. Chem. Mater. 2013, 25, 4926-4935.

(16) Deng, Y. H.; Cai, Y.; Sun, Z. K.; Gu, D.; Wei, J.; Li, W.; Guo, X. H.; Yang, J. P.; Zhao, D. Y. Controlled Synthesis and Functionalization of Ordered Large-Pore Mesoporous Carbons. Adv. Funct. Mater. 2010, $20,3658-3665$.

(17) Deng, Y. H.; Wei, J.; Sun, Z. K.; Zhao, D. Y. Large-Pore Ordered Mesoporous Materials Templated from Non-Pluronic Amphiphilic Block Copolymers. Chem. Soc. Rev. 2013, 42, 4054-4070.

(18) Li, Y. H.; Wei, J.; Luo, W.; Wang, C.; Li, W.; Feng, S. S.; Yue, Q.; Wang, M. H.; Elzatahry, A. A.; Deng, Y. H.; Zhao, D. Y. Tricomponent Coassembly Approach To Synthesize Ordered Mesoporous Carbon/ Silica Nanocomposites and Their Derivative Mesoporous Silicas with Dual Porosities. Chem. Mater. 2014, 26, 2438-2444.

(19) Zhang, J. Y.; Deng, Y. H.; Wei, J.; Sun, Z. K.; Gu, D.; Bongard, H.; Liu, C.; Wu, H. H.; Tu, B.; Schüth, F.; Zhao, D. Y. Design of Amphiphilic ABC Triblock Copolymer for Templating Synthesis of Large-Pore Ordered Mesoporous Carbons with Tunable Pore Wall Thickness. Chem. Mater. 2009, 21, 3996-4005.

(20) Lee, J.; Orilall, M. C.; Warren, S. C.; Kamperman, M.; DiSalvo, F. J.; Wiesner, U. Direct Access to Thermally Stable and Highly Crystalline Mesoporous Transition-Metal Oxides with Uniform Pores. Nat. Mater. 2008, 7, 222-228.

(21) Li, Y. Q.; Bastakoti, B. P.; Imura, M.; Hwang, S. M.; Sun, Z. Q.; Kim, J. H.; Dou, S. X.; Yamauchi, Y. Synthesis of Mesoporous $\mathrm{TiO}_{2} /$ $\mathrm{SiO}_{2}$ Hybrid Films as an Afficient Photocatalyst by Polymeric Micelle Assembly. Chem. - Eur. J. 2014, 20, 6027-6032.

(22) Wei, J.; Li, Y. H.; Wang, M. H.; Yue, Q.; Sun, Z. K.; Wang, C.; Zhao, Y. J.; Deng, Y. H.; Zhao, D. Y. A Systematic Investigation of the Formation of Ordered Mesoporous Silicas Using Poly(ethylene oxide)b-Poly(methyl methacrylate) as the Template. J. Mater. Chem. A 2013, 1, 8819-8827.

(23) Bastakoti, B. P.; Li, Y. Q.; Imura, M.; Miyamoto, N.; Nakato, T.; Sasaki, T.; Yamauchi, Y. Polymeric Micelle Assembly with Inorganic Nanosheets for Construction of Mesoporous Architectures with Crystallized Walls. Angew. Chem., Int. Ed. 2015, 54, 4222-4225.

(24) Bastakoti, B. P.; Ishihara, S.; Leo, S. Y.; Ariga, K.; Wu, K. C.; Yamauchi, Y. Polymeric Micelle Assembly for Preparation of LargeSized Mesoporous Metal Oxides with Various Compositions. Langmuir 2014, 30, 651-659.

(25) Orilall, M. C.; Abrams, N.; Lee, J.; DiSalvo, F.; Wiesner, U. Highly Crystalline Inverse Opal Transition Metal Oxides via a
Combined Assembly of Soft and Hard Chemistries. J. Am. Chem. Soc. 2008, 130, 8882-8883.

(26) Kalra, V.; Lee, J.; Lee, J. H.; Lee, S. G.; Marquez, M.; Wiesner, U.; Joo, Y. L. Controlling Nanoparticle Location via Confined Assembly in Electrospun Block Copolymer Nanofibers. Small 2008, 4, 2067-2073.

(27) Wei, J.; Wang, H.; Deng, Y. H.; Sun, Z. K.; Shi, L.; Tu, B.; Luqman, M.; Zhao, D. Y. Solvent Evaporation Induced Aggregating Assembly Approach to Three-Dimensional Ordered Mesoporous Silica with Ultralarge Accessible Mesopores. J. Am. Chem. Soc. 2011, 133, 20369-20377.

(28) Wei, J.; Sun, Z. K.; Luo, W.; Li, Y. H.; Elzatahry, A. A.; Al-Enizi, A. M.; Deng, Y. H.; Zhao, D. Y. New Insight into the Synthesis of LargePore Ordered Mesoporous Materials. J. Am. Chem. Soc. 2017, 139, $1706-1713$

(29) Brezesinski, T.; Rohlfing, D. F.; Sallard, S.; Antonietti, M.; Smarsly, B. M. Highly Crystalline $\mathrm{WO}_{3}$ Thin Films with Ordered 3D Mesoporosity and Improved Electrochromic Performance. Small 2006, 2, 1203-1211.

(30) Grosso, D.; Boissière, C.; Smarsly, B.; Brezesinski, T.; Pinna, N.; Albouy, P. A.; Amenitsch, H.; Antonietti, M.; Sanchez, C. Periodically Ordered Nanoscale Islands and Mesoporous Films Composed of Nanocrystalline Multimetallic Oxides. Nat. Mater. 2004, 3, 787-792.

(31) Li, Y. H.; Luo, W.; Qin, N.; Dong, J. P.; Wei, J.; Li, W.; Feng, S. S.; Chen, J. C.; Xu, J. Q.; Elzatahry, A. A.; Es-Saheb, M. H.; Deng, Y. H.; Zhao, D. Y. Highly Ordered Mesoporous Tungsten Oxides with a Large Pore Size and Crystalline Framework for $\mathrm{H}_{2} \mathrm{~S}$ sensing. Angew. Chem., Int. Ed. 2014, 53, 9035-9040.

(32) Ren, Y.; Zhou, X. R.; Luo, W.; Xu, P. C.; Zhu, Y. H.; Li, X. X.; Cheng, X. W.; Deng, Y. H.; Zhao, D. Y. Amphiphilic Block Copolymer Templated Synthesis of Mesoporous Indium Oxides with NanosheetAssembled Pore Walls. Chem. Mater. 2016, 28, 7997-8005.

(33) Zhang, Y.; Yang, Q. G.; Yang, X. Y.; Deng, Y. H. One-Step Synthesis of in-situ N-Doped Ordered Mesoporous Titania for Enhanced Gas Sensing Performance. Microporous Mesoporous Mater. 2018, 270, 75-81.

(34) Zhang, Y.; Yue, Q.; Yu, L.; Yang, X. Y.; Hou, X. F.; Zhao, D. Y.; Cheng, X. W.; Deng, Y. H. Amphiphilic Block Copolymers Directed Interface Coassembly to Construct Multifunctional Microspheres with Magnetic Core and Monolayer Mesoporous Aluminosilicate Shell. Adv. Mater. 2018, 30, 1800345-1800354.

(35) Wei, J.; Ren, Y.; Luo, W.; Sun, Z. K.; Cheng, X. W.; Li, Y. H.; Deng, Y. H.; Elzatahry, A. A.; Al-Dahyan, D.; Zhao, D. Y. Ordered Mesoporous Alumina with Ultra-Large Pores as an Efficient Absorbent for Selective Bioenrichment. Chem. Mater. 2017, 29, 2211-2217.

(36) Zhang, J. Y.; Deng, Y. H.; Gu, D.; Wang, S. T.; She, L.; Che, R. C.; Wang, Z. S.; Tu, B.; Xie, S. H.; Zhao, D. Y. Ligand-Assisted Assembly Approach to Synthesize Large-Pore Ordered Mesoporous Titania with Thermally Stable and Crystalline Framework. Adv. Energy Mater. 2011, 1, 241-248.

(37) Fan, J. W.; Lv, M. H.; Luo, W.; Ran, X. Q.; Deng, Y. H.; Zhang, W. X.; Yang, J. P. Exposed Metal Oxide Active Sites on Mesoporous Titania Channels: A Promising Design for Low-Temperature Selective Catalytic Reduction of $\mathrm{NO}$ with $\mathrm{NH}_{3}$. Chem. Commun. 2018, 54, 3783-3786.

(38) Zou, Y. D.; Yang, B. B.; Liu, Y.; Ren, Y.; Ma, J. H.; Zhou, X. R.; Cheng, X. W.; Deng, Y. H. Controllable Interface-Induced CoAssembly toward Highly Ordered Mesoporous $\mathrm{Pt} @ \mathrm{TiO}_{2} / \mathrm{g}-\mathrm{C}_{3} \mathrm{~N}_{4}$ Heterojunctions with Enhanced Photocatalytic Performance. Adv. Funct. Mater. 2018, 28, 1806214.

(39) Xiao, X. Y.; Liu, L. L.; Ma, J. H.; Ren, Y.; Cheng, X. W.; Zhu, Y. H.; Zhao, D. Y.; Elzatahry, A. A.; Alghamdi, A.; Deng, Y. H. Ordered Mesoporous Tin Oxide Semiconductors with Large Pores and Crystallized Walls for High-Performance Gas Sensing. ACS Appl. Mater. Interfaces 2018, 10, 1871-1880.

(40) Zhu, Y. H.; Zhao, Y.; Ma, J. H.; Cheng, X. W.; Xie, J.; Xu, P. C.; Liu, H. Q.; Liu, H. P.; Zhang, H. J.; Wu, M. H.; Elzatahry, A. A.; Alghamdi, A.; Deng, Y. H.; Zhao, D. Y. Mesoporous Tungsten Oxides with Crystalline Framework for Highly Sensitive and Selective 
Detection of Foodborne Pathogens. J. Am. Chem. Soc. 2017, 139, 10365-10373.

(41) Ma, J. H.; Ren, Y.; Zhou, X. R.; Liu, L. L.; Zhu, Y. H.; Cheng, X. W.; Xu, P. C.; Li, X. X.; Deng, Y. H.; Zhao, D. Y. Pt Nanoparticles Sensitized Ordered Mesoporous $\mathrm{WO}_{3}$ Semiconductor: Gas Sensing Performance and Mechanism Study. Adv. Funct. Mater. 2018, 28, 1705268.

(42) Zhou, X. R.; Zhu, Y. H.; Luo, W.; Ren, Y.; Xu, P. C.; Elzatahry, A. A.; Cheng, X. W.; Alghamdi, A.; Deng, Y. H.; Zhao, D. Y. ChelationAssisted Soft-Template Synthesis of Ordered Mesoporous Zinc Oxides for Low Concentration Gas Sensing. J. Mater. Chem. A 2016, 4, 1506415071 .

(43) Wang, Z. R.; Zhu, Y. H.; Luo, W.; Ren, Y.; Cheng, X. W.; Xu, P. C.; Li, X. X.; Deng, Y. H.; Zhao, D. Y. Controlled Synthesis of Ordered Mesoporous Carbon-Cobalt Oxide Nanocomposites with Large Mesopores and Graphitic Walls. Chem. Mater. 2016, 28, 7773-7780.

(44) Luo, W.; Li, Y. H.; Dong, J. P.; Wei, J.; Xu, J. Q.; Deng, Y. H.; Zhao, D. Y. A Resol-Assisted Co-Assembly Approach to Crystalline Mesoporous Niobia Spheres for Electrochemical Biosensing. Angew. Chem., Int. Ed. 2013, 52, 10505-10510.

(45) Li, Y. H.; Zhou, X. R.; Luo, W.; Cheng, X. W.; Zhu, Y. H.; ElToni, A. M.; Khan, A.; Deng, Y. H.; Zhao, D. Y. Pore Engineering of Mesoporous Tungsten Oxides for Ultrasensitive Gas Sensing. Adv. Mater. Interfaces 2019, 6, 1801269.

(46) Chen, Y.; Xu, P. C.; Li, X. X.; Ren, Y.; Deng, Y. H. HighPerformance $\mathrm{H}_{2}$ Sensors with Selectively Hydrophobic Micro-Plate for Self-Aligned Upload of Pd Nanodots Modified Mesoporous $\operatorname{In}_{2} \mathrm{O}_{3}$ Sensing-Material. Sens. Actuators, B 2018, 267, 83-92. 